\title{
Midlatitude $F$ region peak height changes in response to interplanetary magnetic field conditions and modeling results
}

\author{
Estefania Blanch ${ }^{1}$ and David Altadill ${ }^{1}$ \\ Received 11 June 2012; revised 18 October 2012; accepted 18 October 2012; published 13 December 2012.
}

[1] The response of the electron density peak height of the $\mathrm{F} 2$ region, hmF2, to geomagnetic storms has been investigated and a characteristic behavior of the peak height disturbance in relation to local-time, season and conditions of the interplanetary magnetic field has been obtained. The experimental results support the storm scenario which the change in the thermospheric wind is the main physical mechanism raising the ionospheric peak height. A real-time forecasting tool modeling the hmF2 disturbance, $\Delta \mathrm{hmF}$, by analytical time-dependent functions has been developed. The empirical model predicts $\Delta \mathrm{hmF} 2$ for latitudes of the Iberian Peninsula with an $86 \%$ of success and without false alarms. The behavior of the model fits to the experimental observations at other latitudes and longitudes within Europe which would allow extending its usefulness at wider latitudinal ranges.

Citation: Blanch, E., and D. Altadill (2012), Midlatitude F region peak height changes in response to interplanetary magnetic field conditions and modeling results, J. Geophys. Res., 117, A12311, doi:10.1029/2012JA018009.

\section{Introduction}

[2] Geomagnetic storms and their effects on the ionospheric behavior are generated by the changes in the solar wind and interplanetary magnetic field (IMF) interacting with the magnetosphere. Several mechanisms are involved to explain the ionospheric effects occurring during geomagnetic storms. These mechanisms mainly fall into two categories; Joule heating of the high latitude thermosphere [e.g., FullerRowell et al., 1994] driving neutral wind surges and causing composition changes [e.g., Prölss, 1993], and electrodynamics processes [Heelis, 2004] driven by the penetration of electric field [Spiro et al., 1988] and the disturbance dynamo [Blanc and Richmond, 1980]. To date there exist many articles and reviews devoted to geomagnetic storms and their effects on the ionosphere [e.g., Rishbeth, 1991; Prölss, 1995; Buonsanto, 1999; Kelley et al., 2004; Mendillo, 2006; Balan et al., 2010]. These ionospheric effects are typically known as positive or negative ionospheric storms according to the increase or decrease of the electron density respect to the quiet average behavior and they are dependent of the local time. Negative storms are predominantly observed during nighttime, while positive storms are usually associated with daytime periods [e.g., Lu et al., 2008]. Positive and negative effects also have a seasonal dependence [e.g., Fuller-Rowell

\footnotetext{
${ }^{1}$ Observatori de l'Ebre, CSIC, Universitat Ramon Llull, Roquetes, Spain.

Corresponding author: E. Blanch, Observatori de l'Ebre, CSIC, Universitat Ramon Llull, Horta Alta, 38, E-43520 Roquetes, Spain. (eblanch@obsebre.es)

(C)2012. American Geophysical Union. All Rights Reserved. 0148-0227/12/2012JA018009
}

et al., 1996]. Although negative effects are mostly observed at night in summer midlatitude, both positive and negative storm phases in winter midlatitude have been observed during large geomagnetic storms [Araujo-Pradere et al., 2004]. The effects of geomagnetic storms on the ionosphere are not limited to density perturbations but also in its vertical structure, causing variations in the height of maximum density, $\mathrm{hmF} 2$, which uses to increase systematically few hours after the onset of the storm at midlatitudes [e.g., Prölss, 1993; Prölss and Očko, 2000; Paznukhov et al., 2009].

[3] Nowadays emphasis is put not only on the knowledge of the physical mechanisms causing ionospheric storms but also on the modeling and prediction of these effects. Many efforts have been done in the recent years to model and predict the effects of geomagnetic storms on the electron density both empirically [e.g., Araujo-Pradere et al., 2002; Tsagouri and Belehaki, 2006] and physically based [e.g., FullerRowell et al., 2007; Lei et al., 2008; Balan et al., 2010]. However, fewer investigations have been made to develop a height disturbance model or to validate the storms effects on the height with the physically based models. The empirical STORM correction model [Araujo-Pradere et al., 2002] included in the International Reference Ionosphere model, IRI, [Bilitza, 2001] is insensitive to height disturbances [e.g., Paznukhov et al., 2009]. Deminova et al. [1998] constructed a global empirical model for the variations of the ionospheric characteristic h'F2 (the virtual height of the F2 layer) caused by geomagnetic storms and magnetospheric substorms but the model is only valid for the nighttime sector when variations of h'F2 are similar to those of hmF2. Fedrizzi et al. [2008] have demonstrated the appropriate use of a physically based model to simulate the effects on the hmF2 caused by two strong storms. The shortage on modeling the height disturbances caused by geomagnetic storms is mostly due to 

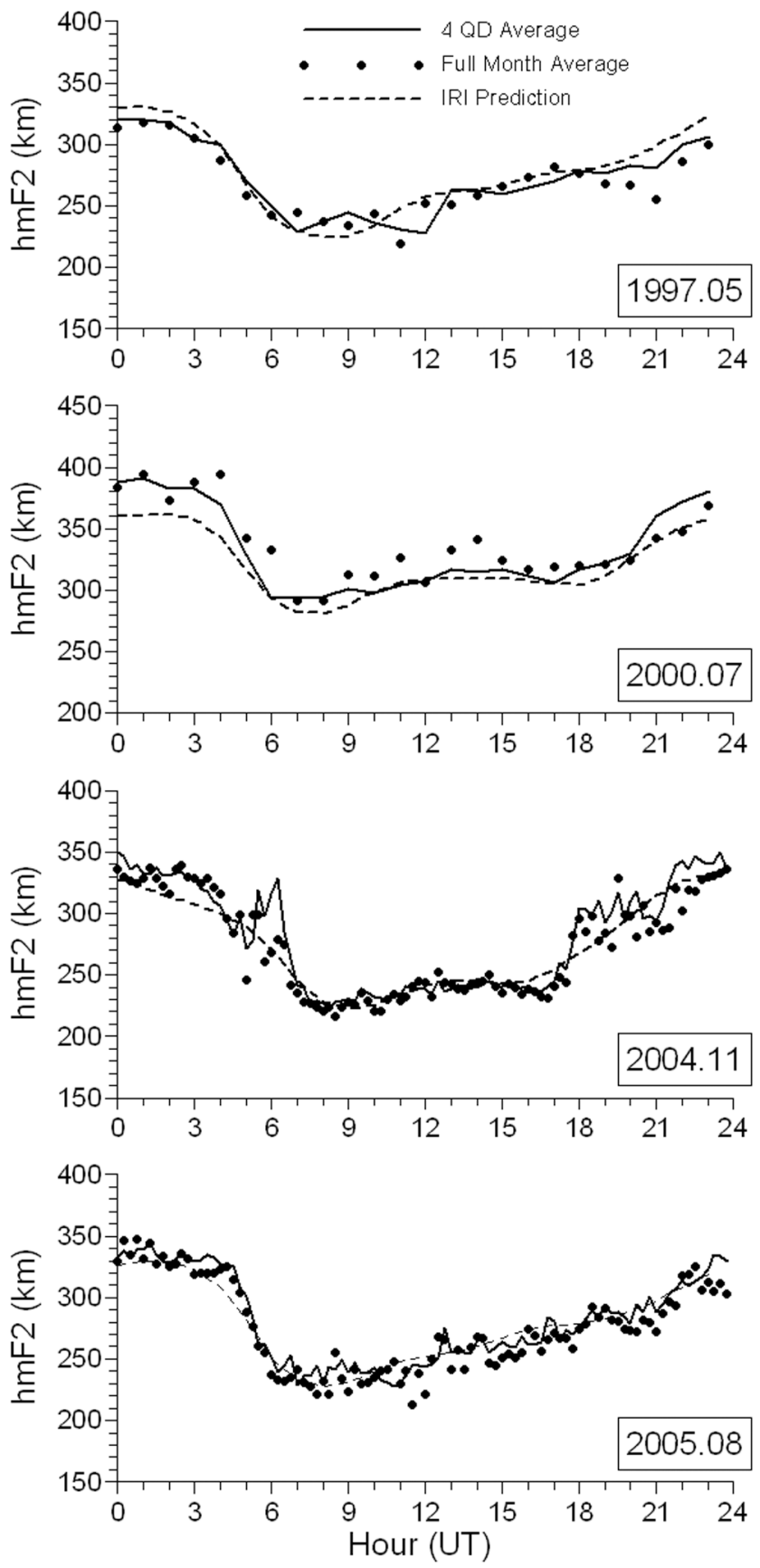

Figure 1. Diurnal variation of $h m F 2$ for the reference quiet day as obtained from the four quietest days adjacent to the disturbed day (black line), the full month average profile (black dots) and the IRI predictions for Ebro station (dashed black line). The rectangles indicate the year and month when particular storm events had occurred (Table 1).

the scarcity of true height data and to an inaccurate formulation of the hmF2 characteristic [e.g., Shimazaki, 1955; Prölss and Očko, 2000].

[4] The aim of this work is to investigate the behavior of the $\mathrm{hmF} 2$ disturbances caused during intense geomagnetic storms and to develop an empirical model able to predict such height disturbances at midlatitudes in near real time. Our study takes advantage of the large amount of data recorded by Digisondes located in Spain over significant time interval which encompasses from 1995 to 2007. Thirtytwo intense storm events which occurred for 1995-2007 have been analyzed and allowed to obtain the typical behavior of the disturbed hmF2 in relation to local-time, season and conditions of the IMF.

\section{Data and Methodology}

[5] To carry forward this research, we have analyzed hourly values of the vertical electron density profiles $\mathrm{N}(\mathrm{h})$ calculated from the vertical incidence ionograms with the true height profile inversion tool "NHPC" [Huang and Reinisch, 1996a]. The ionograms have been recorded at Spanish stations "Observatorio del Ebro" $\left(\mathrm{OE} ; 40.5^{\circ} \mathrm{N}\right.$, $\left.0.5^{\circ} \mathrm{E}\right)$ and "El Arenosillo" (EA; $\left.37.1^{\circ} \mathrm{N}, 353.3^{\circ} \mathrm{E}\right)$. These stations have furnished the ionograms revised and scaled manually from 1995 to 2007, allowing to compute accurate $\mathrm{N}(\mathrm{h})$ profiles and to obtain accurate values of the true ionospheric peak height, $h m F 2$. The hmF2 disturbance, $\Delta \mathrm{hmF}$, has been obtained as the differences between the hmF2 values measured on the event day and the reference quiet day. The ionospheric reference quiet day for each storm event has been obtained by applying the averaged representative profile (ARP) [Huang and Reinisch, 1996b] to the four quietest days closest to the disturbed one. Figure 1 shows that the results are equivalent using as reference day the average profile for a full month of revised data or the IRI prediction (for Spanish latitudes). We did consider a disturbance in $\mathrm{hmF} 2$ to be significant when $\Delta \mathrm{hmF} 2>2 \sigma$ for at least 2 consecutive hours, where $\sigma$ means the standard deviation at a given time of the quiet days in relation to the average reference quiet day. The reason of using the four quietest days adjacent to the disturbed day to obtain the reference quiet day is due to a compromise between working with good quality data and data process needed. Though Ebro and El Arenosillo furnished revised data, this is not the case for most of the ionospheric stations which provide automatic scaling only. However, we pretend to apply this kind of analysis to any available station. Therefore, it would be required to revise large amount of data to get a reference quiet day based on the monthly average profile for other ionospheric stations, making this not doable in a reasonable time. Moreover, averaging over available autoscaled profiles to obtain the reference quiet day might provide biased and noisy diurnal variation, especially during summer when the occurrence of the sporadic $E$ layers might corrupt the quality of the auto-scaling.

[6] The helio-geomagnetic data used here, encompassing the same interval as above, 1995-2007, have been obtained from several sources with a data sampling of one hour. The geomagnetic activity indices AE (auroral electrojet) and Dst (disturbance) have been obtained from Kyoto WDC (http:// swdcwww.kugi.kyoto-u.ac.jp/) and the solar wind and IMF data have been obtained from OMNI database (http://omniweb.gsfc.nasa.gov). We have applied the criterion of Gonzalez and Tsurutani [1987] (IMF Bz $\leq-10 \mathrm{nT}$ lasting for interval $\geq 3 \mathrm{~h}$ ) to identify the time intervals when intense geomagnetic storms [Gonzalez et al., 1994] might occur, leading to more than 70 intervals. Keeping in mind the picture of a typical geomagnetic storm as seen by the Dst index, those intervals in which the main phase of the storm develops into two steps [Kamide et al., 1998] have not been taken into 
Table 1. List of the Disturbed Periods Analyzed in this Study ${ }^{a}$

\begin{tabular}{|c|c|c|c|c|}
\hline Disturbed Days & Station & $\begin{array}{l}\text { Dst Min. } \\
\quad(\mathrm{nT})\end{array}$ & $\mathrm{T}_{0}$ & Quiet Days \\
\hline 18-19 Oct 1995 & EA & -127 & 20 & $25,26,28,29$ Oct 1995 \\
\hline 15-16 May 1997 & OE, EA & -115 & 6 & 12,13,19,23 May 1997 \\
\hline 10-11 Oct 1997 & OE, EA & -130 & 21 & 5,15,16,19 Oct 1997 \\
\hline 06-07 Nov 1997 & $\mathrm{OE}$ & -110 & 24 & $\begin{array}{l}\text { 19,21 Oct } 1997 \\
\text { 2,21 Nov } 1997\end{array}$ \\
\hline 10-11 Mar 1998 & $\mathrm{OE}$ & -116 & 16 & 7,8,9,18 Mar 1998 \\
\hline 06-07 Aug 1998 & $\mathrm{OE}$ & -138 & 8 & $\begin{array}{c}27 \text { Jul } 1998 \\
9,15,16 \text { Aug } 1998\end{array}$ \\
\hline 18-19 Oct 1998 & OE, EA & -112 & 3 & $4,5,14,16$ Oct 1998 \\
\hline 13-14 Jan 1999 & OE, EA & -112 & 16 & 3,19,26,30 Jan 1999 \\
\hline 18-19 Feb 1999 & OE, EA & -123 & 6 & 2,9,20,26 Feb 1999 \\
\hline 22-23 Sep 1999 & EA & -173 & 20 & 8,20,24,25 Sep 1999 \\
\hline 06-07 Apr 2000 & OE, EA & -288 & 17 & $\begin{array}{l}\text { 26,27 Mar } 2000 \\
14,18 \text { Apr } 2000\end{array}$ \\
\hline 15-16 Jul 2000 & OE, EA & -301 & 19 & $6,7,24,25$ Jul 2000 \\
\hline $17-18$ Sep 2000 & OE, EA & -201 & 21 & $10,11,14,22$ Sep 2000 \\
\hline $28-29$ Oct 2000 & OE, EA & -127 & 22 & $\begin{array}{c}20,21 \text { Oct } 2000 \\
2,3 \text { Nov } 2000\end{array}$ \\
\hline 11-12 Apr 2001 & $\mathrm{OE}$ & -271 & 16 & $\begin{array}{c}26 \text { Mar } 2001 \\
19,24,25 \text { Apr } 2001\end{array}$ \\
\hline 18-19 Apr 2001 & $\mathrm{EA}, \mathrm{OE}$ & -114 & 2 & 19,24,25,27 Apr 2001 \\
\hline 21-22 Oct2001 & EA & -187 & 17 & $17,18,24,26$ Oct 2001 \\
\hline $28-29$ Oct 2001 & $\mathrm{OE}$ & -157 & 4 & $\begin{array}{c}25,26,27 \text { Oct } 2001 \\
3 \text { Nov } 2001\end{array}$ \\
\hline 06-07 Nov 2001 & $\mathrm{OE}$ & -292 & 2 & $\begin{array}{l}25,26 \text { Oct } 2001 \\
3,14 \text { Nov } 2001\end{array}$ \\
\hline 04-05 Sep 2002 & $\mathrm{OE}$ & -109 & 2 & $\begin{array}{l}24,25 \text { Aug } 2002 \\
20,23 \text { Sep } 2002\end{array}$ \\
\hline 07-08 Sep 2002 & $\mathrm{OE}$ & -181 & 18 & $\begin{array}{l}24,25 \text { Aug } 2002 \\
20,23 \text { Sep } 2002\end{array}$ \\
\hline 01-02 Oct 2002 & $\mathrm{OE}$ & -176 & 8 & $23,24,25,29$ Sep 2002 \\
\hline 29-30 May 2003 & EA & -144 & 18 & $\begin{array}{c}\text { 16,17,18 May } 2003 \\
\text { 5 Jun } 2003\end{array}$ \\
\hline 17-18 Aug 2003 & EA & -148 & 4 & 4,5,16,27 Aug 2003 \\
\hline 20-21 Nov 2003 & EA & -422 & 12 & $8,27,28,29$ Nov 2003 \\
\hline 22-23 Jan 2004 & $\mathrm{OE}$ & -149 & 11 & $12,14,29,31$ Jan 2004 \\
\hline 22-23 Jul /2004 & $\mathrm{OE}$ & -101 & 20 & $\begin{array}{r}\text { 9,21 Jul } 2004 \\
\text { 3,4 Sep } 2004\end{array}$ \\
\hline 07-08 Nov 2004 & OE, EA & -373 & 20 & 2,5,6,15 Nov 2004 \\
\hline 12-13 Jun 2005 & EA & -106 & 17 & $10,20,27,28$ Jun 2005 \\
\hline 24-25 Aug 2005 & OE, EA & -216 & 9 & $11,12,20,28$ Aug 2005 \\
\hline 31 Aug-01 Sep 2005 & $\mathrm{OE}$ & -131 & 13 & $\begin{array}{c}\text { 20,28,30 Aug } 2005 \\
\text { 8 Sep } 2005\end{array}$ \\
\hline 14-15 Apr 2006 & OE, EA & -111 & 3 & 1,2,3,12 Apr 2006 \\
\hline
\end{tabular}

${ }^{a}$ The ionospheric stations having contemporary data with the storms events are indicated (OE and EA mean "Observatorio del Ebro" and "El Arenosillo" stations respectively). The value of the minimum Dst is provided as indicator of the storm intensity. $\mathrm{T}_{0}$ means the time (in UT) when IMF $\mathrm{Bz} \leq-10 \mathrm{nT}$ (the so-called reference time). The four quietest days adjacent to the disturbed day used to obtain the ionospheric reference quiet day are also indicated. Note that the data consist of 45 samples of 2-day ionospheric data intervals: 25 samples for $\mathrm{OE}$ and 20 samples for EA.

account to simplify the analyses. Those storms having slow varying main phase have not been considered either because we have observed that $\Delta \mathrm{hmF} 2$ never raises $2 \sigma$ for two consecutive hours, i.e. this type of storms do not produce significant disturbance in $\mathrm{hmF} 2$ according to our criterion. Moreover, not all the above intervals have contemporary ionospheric and solar wind data. That is why the analysis has been limited to thirty-two storm events.

[7] The study of the $\Delta \mathrm{hmF} 2$ for each storm event consist on the analysis of 2-day intervals (starting at 0:00 UT) in which the initial and the main phases of the storm develop during the first day of the interval. This way we can fully observe the effects caused in the hmF2 for the main phase of the storm and, at least, for the following $24 \mathrm{~h}$ of the recovery phase. Table 1 lists the thirty-two 2-day intervals of the storm events analyzed in this study as well as the four quietest days used to obtain the respective ionospheric reference quiet day. Note that although the database consists of 32 storm events in fact it consist of 45 samples of 2-day ionospheric data intervals because two different ionospheric stations have been analyzed (OE and EA).

[8] In order to obtain the response of $\mathrm{hmF} 2$ to intense geomagnetic storms and to model it analytically we first look for a reference time, then we obtain the pattern of the response of $\mathrm{hmF} 2$ (i.e., the typical behavior of $\Delta \mathrm{hmF} 2$ ) and finally we examine the relationships of that response to the behavior of the solar wind (dynamic pressure, plasma velocity and density), interplanetary magnetic field and other parameters derived from them and geomagnetic activity indices (AE and Dst).

\section{Typical Behavior of the hmF2 Disturbance}

[9] Recent experimental studies show systematic rising of the hmF2 occurring during disturbed geomagnetic conditions. Denton et al. [2009] have analyzed changes in hmF2 occurring after the onset of magnetospheric convection associated with high-speed solar wind streams arriving at the Earth's magnetosphere. They have found that hmF2 increases by approximately $20 \mathrm{~km}$ at convection onset. Paznukhov et al. [2009] have reported experimental evidence that hmF2 at midlatitudes systematically raises (well above the reference quiet day values) short after the beginning of an intense geomagnetic storm. Figure 2 depicts the behavior of hmF2 for a particular storm showing the significant rising of hmF2 respect to the reference quiet day. The disturbed behavior, $\Delta \mathrm{hmF} 2$, for this event shows two consecutive pulses (in the shape of a bell), the first coinciding in time with the main phase of the storm and the second happening when the station gets the dusk sector. In addition, Paznukhov et al. [2009] have reported some dependence in the time of the ionospheric density reaction with the local time and have indicated the potential usefulness for predicting the ionospheric storm effects. They took into account the storm commencement (SC) as the reference time to get a first approach of the response-time of the ionosphere.

\subsection{Time of Reference}

[10] The search of a reference time for the hmF2 disturbance caused during storms is associated with the phases of a geomagnetic storm. The development of a typical geomagnetic storm as seen by the Dst index usually shows three distinct phases [e.g., Parkinson, 1983]: 1) the initial phase, which does not always occur, begins with a sudden impulse, called storm commencement (SC) and it is attributed to a compression of the magnetosphere by an interplanetary shock wave; 2) the main phase, which is attributed to an enhancement of the magnetospheric ring current produced by the injection of energetic particles into the inner magnetosphere; and 3) the recovery phase, which is related to the decay of the ring current.

[11] The SC is often chosen as the reference time of the origin of a geomagnetic disturbance but not all geomagnetic storms are preceded by this impulse. Moreover, the beginning of the main phase of the geomagnetic storms can be 


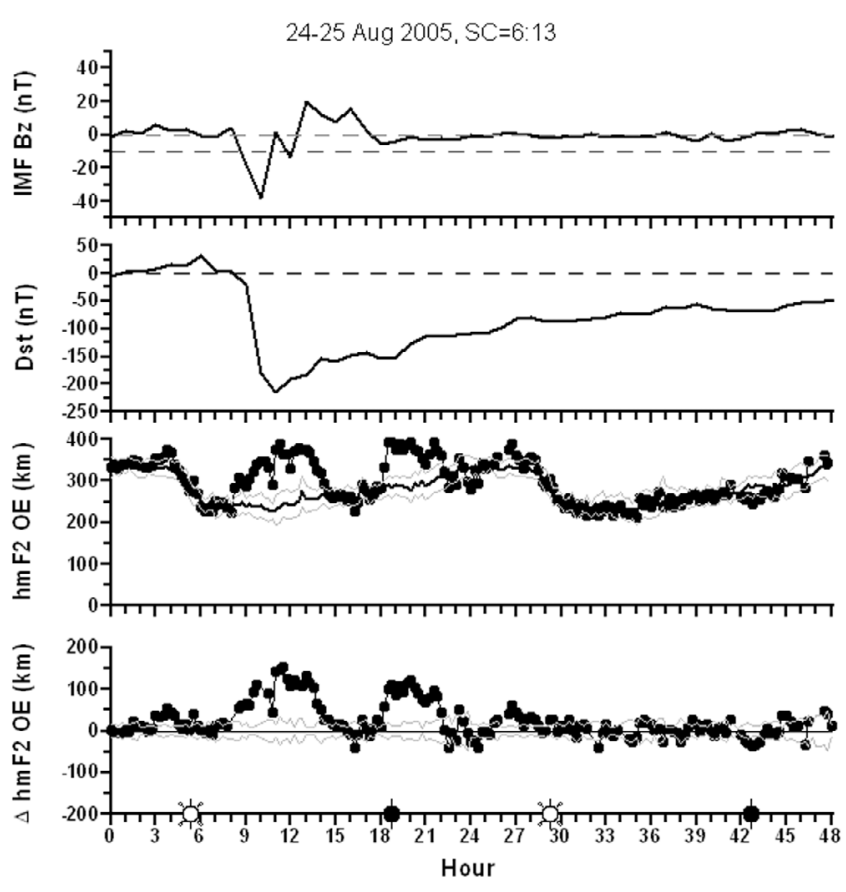

Figure 2. Example for the geomagnetic storm effects occurred on 24 August 2005 as seen from "Observatorio del Ebro" station. From top: interplanetary magnetic field (Bz component), magnetic activity index Dst, comparison of experimental hmF2 during the disturbed day (dotted line) with the quiet hmF2 pattern (black thick line) and hmF2 disturbance with respect to a quiet day. The thin gray lines indicate the standard deviation expected for a quiet day. The white and black suns in the horizontal axis indicate respectively the sunrise and sunset at ground level.

significantly delayed from the $\mathrm{SC}$, this delay may be larger than ten hours. We did evaluate the time delay of hmF2 disturbance from the time of the SC and get to the conclusion that this delay does no present any characteristic timing. Those storms with long initial phase bring about longer delay of the hmF2 disturbance compared to the storms having short initial phase. Thus, the $\mathrm{SC}$ is not a good choice as reference time for $\mathrm{hmF} 2$ disturbance because of both it cuts the sample to only those geomagnetic storms having SC and the delay of the disturbance from the SC depends on the length of the initial phase of the geomagnetic storms.

[12] We get a different picture by relating the delay of $\mathrm{hmF} 2$ disturbance to the behavior of the $\mathrm{Bz}$ component of the IMF. Gonzalez and Tsurutani [1987] have found and suggested that $\mathrm{Bz} \leq-10 \mathrm{nT}$ lasting at least three hours may be used to predict intense geomagnetic storms and they related the moment when $\mathrm{Bz} \leq-10 \mathrm{nT}$ to the onset of the main phase. We have evaluated the delay of hmF2 disturbance in relation to the moment when $\mathrm{Bz}$ drops below $-10 \mathrm{nT}$ and we have found this delay to be confined between 1 to $4 \mathrm{~h}$ approximately regardless of local time and of the intensity of the storm. Thus, we have chosen as a reference time the moment when $\mathrm{Bz} \leq-10 \mathrm{nT}$ for those cases that fulfill the criterion of Gonzalez and Tsurutani [1987]. Therefore, further analysis to obtain the pattern of the response of $\mathrm{hmF} 2$ to intense geomagnetic storms consider this moment as a zero time or time of reference $\left(\mathrm{T}_{0}\right)$.

\subsection{Superposed Epoch Analysis}

[13] We have carried out a superposed epoch analysis to investigate the typical pattern of the response of hmF2 to geomagnetic storms; i.e., the expected average behavior of $\Delta \mathrm{hmF} 2$. The superposed epoch analysis has been performed for $24 \mathrm{~h}$ intervals elapsed from the reference time defined above (time when $\mathrm{Bz} \leq-10 \mathrm{nT}$ ). The 24-h intervals correspond to the 45 ionospheric samples listed in Table 1. Note that the position of each ionospheric station at the reference time for all the events distributes over all the local time sectors (Figure 3). The average behavior $\left(\bar{X}(t)=\sum_{i} X_{i}(t) / N\right)$ and the standard deviation $\left(\sigma^{2}(t)=\sum_{i}\left(X_{i}(t)-\bar{X}(t)\right)^{2} / N\right)$ of the distribution of $\Delta \mathrm{hmF} 2$ have been calculated. The same analysis has been also applied to the 32 events for the solar wind, interplanetary magnetic field and geomagnetic activity data to find a possible correlation with the behavior of $\Delta \mathrm{hmF} 2$. Figure 4 depicts the result of the aforementioned superposed epoch analysis for some of the data series and it clearly shows that the average behavior of all data sets manifest significant rate of change nearby the so-called reference time. The latter is true except for the solar wind related data; i.e., dynamic pressure, density and velocity (not shown). Thus, the disturbance in hmF2 correlates with the IMF and geomagnetic activity data better than it does with the solar wind. The average height disturbance lags behind the reference time by two hours approximately whereas the averages of the IMF and of the geomagnetic activity indices react quasi-simultaneously with the reference time. Therefore, the behavior of the IMF and the geomagnetic activity can be useful for predicting $\Delta \mathrm{hmF} 2$.

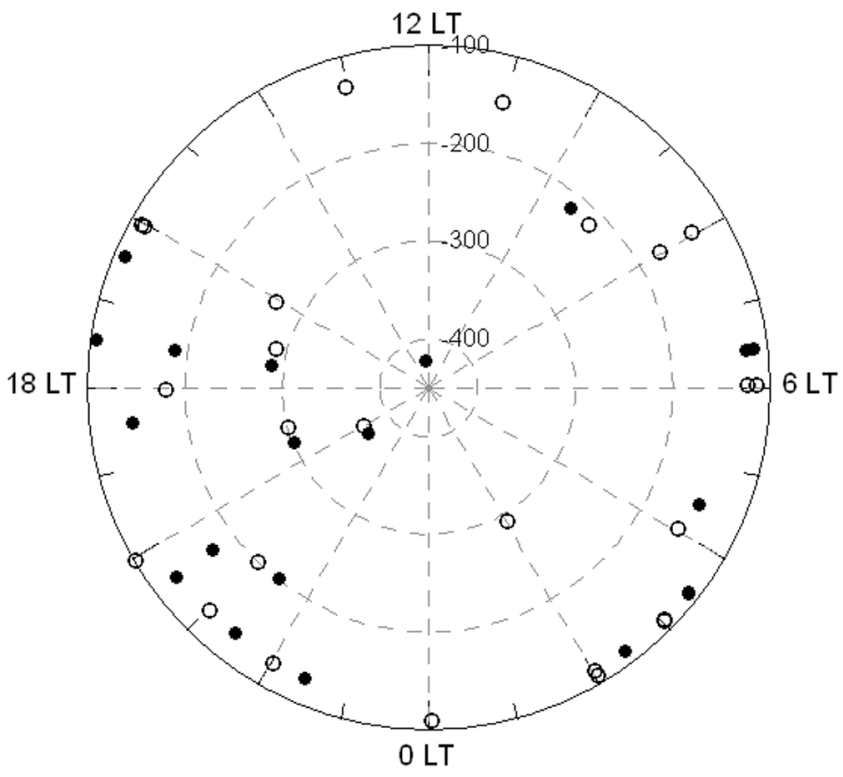

Figure 3. Position, in local time, of each station at the moment when IMF $\mathrm{Bz} \leq-10 \mathrm{nT}$ (reference time) for each storm period analyzed (Table 1). The open circles correspond to the events recorded at $\mathrm{OE}$ and full dots to those recorded at EA. The radius indicates the intensity of the storm (Dst minimum). 


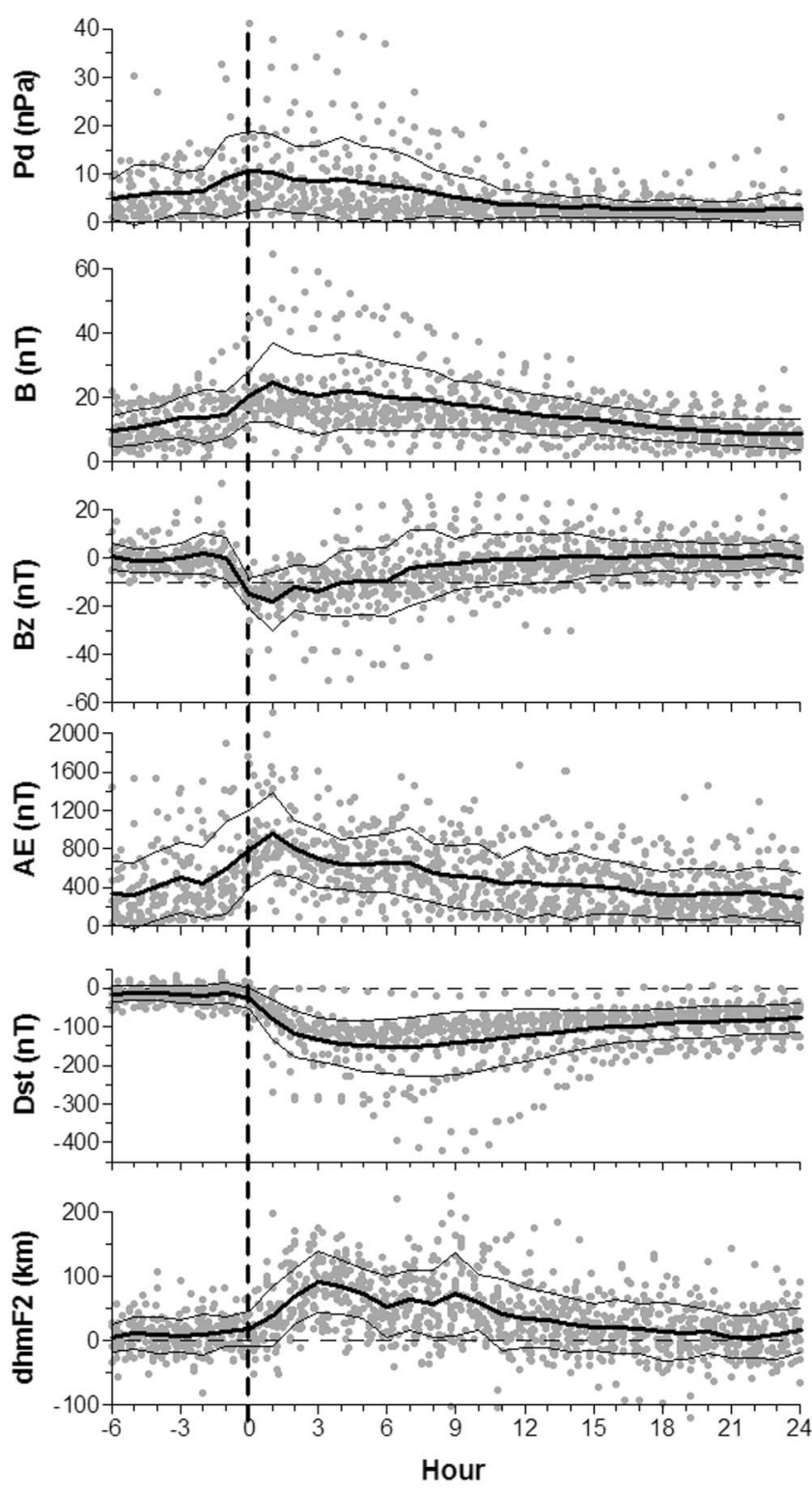

Figure 4. Superposed epoch analysis corresponding to the 24-h intervals listed in Table 1. The axis time elapses from the moment when Bz component of the IMF drops below $-10 \mathrm{nT}$. From top to bottom: Dynamic pressure, total interplanetary magnetic field, Bz component of IMF, auroral electrojet index, Dst index and hmF2 disturbance. Black thick lines correspond to the average behavior and black thin lines denote the region within one standard deviation of the mean for each parameter.

[14] The results show that the average disturbance of hmF2 is well correlated with the averages of the IMF and geomagnetic activity data and that $\Delta \mathrm{hmF} 2$ has better agreement with the AE index and the IMF data than it has with the solar wind and Dst index. As it is well known, the $\mathrm{AE}$ index is frequently used to monitor the substorm activity and it is a good proxy for energy deposition at auroral latitudes [e.g., Rostoker et al., 1980]. In addition, changes or fluctuations in the solar wind electric fields are responsible for initiating magnetospheric substorms [Kamide, 2001].
Thus, our results suggest that substorm expansions play significant role on the hmF2 disturbance caused during intense storms and this fact should be taken into account for modeling purposes.

\subsection{Physical Mechanisms}

[15] The changes in the solar wind and interplanetary magnetic field interacting with the magnetosphere causes an increase of the energy input at high latitudes driving convection electric fields and ionospheric currents. This energy input added to particle precipitation results in a heating of the auroral region by Joule dissipation which in turn produces traveling atmospheric disturbances (TADs), wind surges, changes in the global wind circulation and in the neutral gas composition [e.g., Prölss, 1993; Fuller-Rowell et al., 1994] and electrodynamics processes [Heelis, 2004]. There are two main mechanisms to explain the height changes at midlatitudes occurred during geomagnetic storms. The heating of the high latitude thermosphere generates wind surges driving horizontal equatorward-directed winds [e.g., Prölss and Očko, 2000] and causes thermal expansion driving vertical winds also [e.g., Fedrizzi et al., 2008] which move the plasma along the magnetic field lines and raise the ionospheric peak height. Electric field penetration can also cause an uplift of the F2 layer at midlatitudes [e.g., Prölss, 1995; Huang et al., 2005] but the uplift resulting from the electric field penetration must occur practically simultaneously with the onset of the storm. However, our results indicate that the height reacts by one to four hours after the onset of the main phase and these results are consistent with the storm scenario described by Prölss [1993] which predicts a pulse-like increase of the ionospheric peak height at midlatitude from 1 to $3 \mathrm{~h}$ after the energy input at high latitudes. Though our results do not exclude the electric field penetration as potential mechanism for the $\Delta \mathrm{hmF} 2$, we do not consider it as the main mechanism at midlatitudes. These results are in agreement also with those reported at other midlatitude stations for particular events [Paznukhov et al., 2009], where experimental evidence of the equatorward propagation of the $\Delta \mathrm{hmF} 2$ was demonstrated. According to the main driving mechanism for the $\Delta \mathrm{hmF} 2$ which relates to the disturbed thermospheric neutral winds, we should observe some dependence on the local time and season [e.g., Fuller-Rowell et al., 1994; Fedrizzi et al., 2008]. Overnight, the equatorward background neutral winds favors the penetration of the thermospheric disturbances to the midlatitudes whereas the opposite apply during daytime. The seasonal behavior of the background thermospheric winds helps the equatorward propagation of the disturbance at summer whereas they may break the penetration of the disturbance to midlatitudes at winter [Fuller-Rowell et al., 1996]. Araujo-Pradere et al. [2004] have found a seasonal-latitudinal dependence in the ionosphere response to storms that can explain the equatorward propagation of the disturbance at midlatitude winter hemisphere.

[16] A detailed inspection on the average behavior of $\Delta \mathrm{hmF} 2$ resulting from the superposed epoch analysis reveals that a two pulse-like pattern becomes apparent. The zoom of the average behavior depicted in Figure 4 (bottom) clearly shows this pattern (Figure 5). Moreover, the behavior of $\Delta \mathrm{hmF} 2$ for all the events reveals distinct pattern of time- 


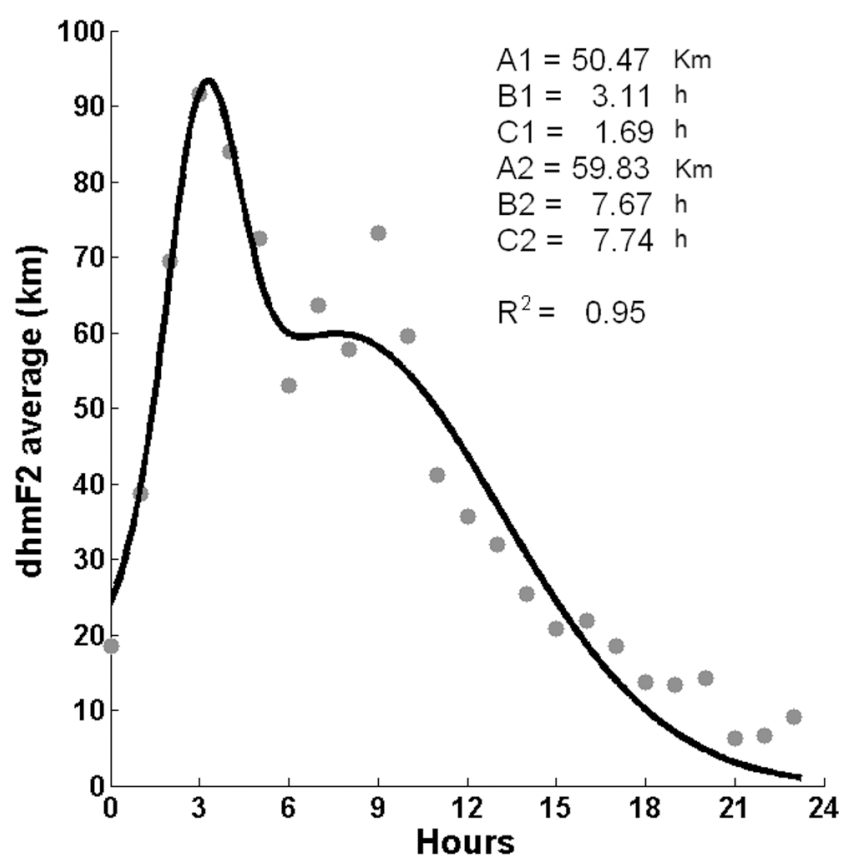

Figure 5. Average behavior of $\Delta \mathrm{hmF} 2$ resulting from the superposed epoch analysis (gray dots) compared with the best two-pulse time dependent Gaussian fit (black thick line). The coefficients of the Gaussian fitting (equation (1)) and the coefficient of determination are indicated.

development which is in relation to the local time of the ionospheric station at the reference time. Figure 6 depicts several examples of this distinct pattern of time-development of $\Delta$ hmF2: a) $\Delta$ hmF2 shows a sole uplift for those events starting at the midnight-dawn sector (e.g., Figure 6a), b) $\triangle \mathrm{hmF} 2$ shows two consecutive uplifts for those events starting at the dusk-midnight sector (e.g., Figure 6b), and c) $\Delta \mathrm{hmF} 2$ shows two separate uplifts for those events starting at the daytime sector (e.g., Figure 6c). The only difference between Figures $6 \mathrm{~b}$ and $6 \mathrm{c}$ is the time lag between the two uplifts; the second uplift recorded for Figure $6 \mathrm{~b}$ occurs after midnight and that recorded for Figure $6 \mathrm{c}$ does occur after sunset. Moreover, such a distinct pattern which is local time dependent also depends on the season. To some extent, the later might reflect the effect of the seasonal behavior of the background thermospheric winds [Fuller-Rowell et al., 1996].

[17] We suggest the following potential explanation for arguing the above three distinct patterns of $\Delta \mathrm{hmF} 2$. The single uplift for the events Type A may result from the quasisimultaneous effects of the TADs and equatorward wind surges. The first uplift for the events Type B and Type C may result from the effects of the TADs and the second one can result from the equatorward wind surges. Prölss [1993, Figure 1] qualitatively explains the time sequence of thermospheric-ionospheric storm and that storm scenario agrees with the experimental results obtained here. In addition, the simulation by Fuller-Rowell et al. [1994] shows that the storm surges can occupy a very large area $12 \mathrm{~h}$ after the beginning of a storm, influencing practically the whole nightside midlatitude ionosphere. Thus, those stations initially located on the day-time sector at the reference time experience a first uplift as consequence of the storm-time TADs of auroral origin. When these stations "drift" to the nighttime sector later after the beginning of the storm they experience the so-called second uplift as consequence of a superposition of the background thermospheric winds (equatorward at night) with the storm-time wind.

\section{Modeling Approach}

[18] In order to predict in near real time the height disturbances at midlatitudes caused during intense storms, we have first investigated the potential precursors that may alert the development of the pulse-like disturbance observed at $\Delta \mathrm{hmF} 2$ (Figure 6). The events analyzed in this research (Table 1) relate with disturbed intervals that fulfill the
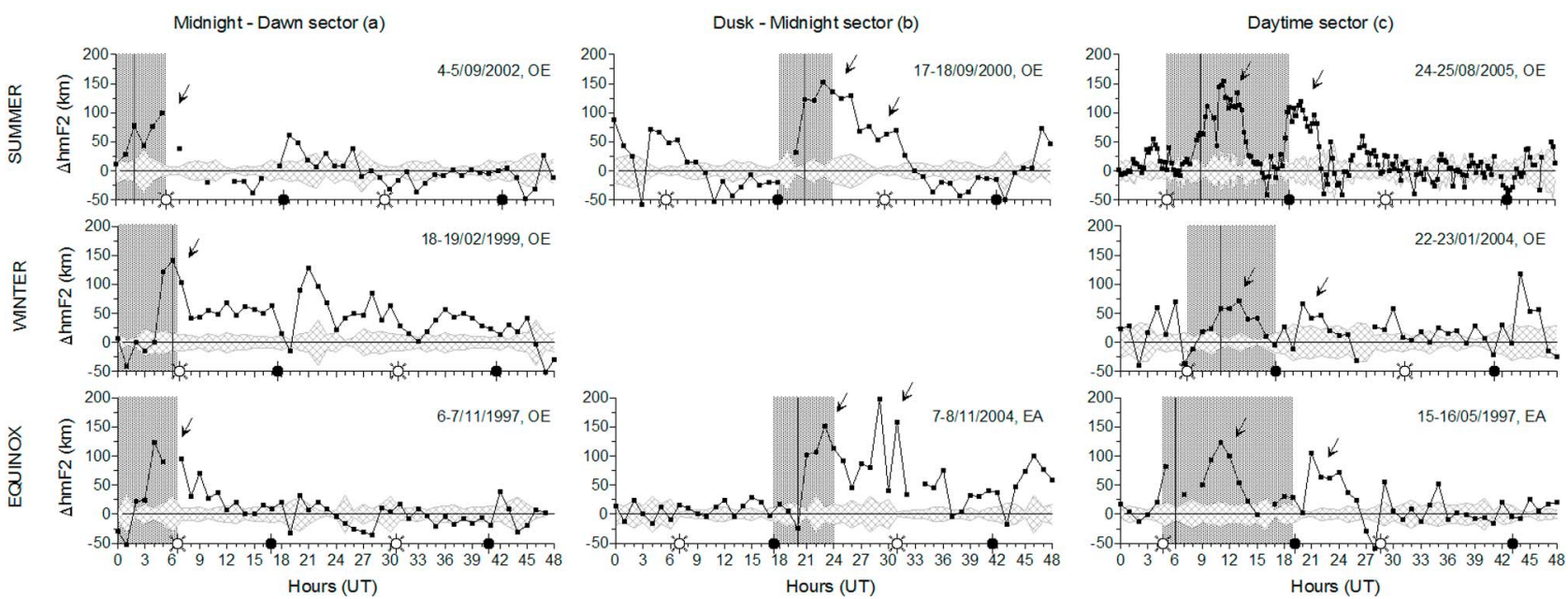

Figure 6. Behavior of $\Delta \mathrm{hmF} 2$ for three different local time sectors (a-c) (midnight-dawn, dusk-midnight and daytime) and season (from up to down: summer, winter and equinox) for the indicated disturbed periods. Shaded areas indicate the local time sector for each case. Vertical black lines indicate the reference time. White and black suns in the horizontal axis mean sunrise and sunset respectively. Tilted arrows indicate the observed pulses at $\Delta \mathrm{hmF} 2$. 

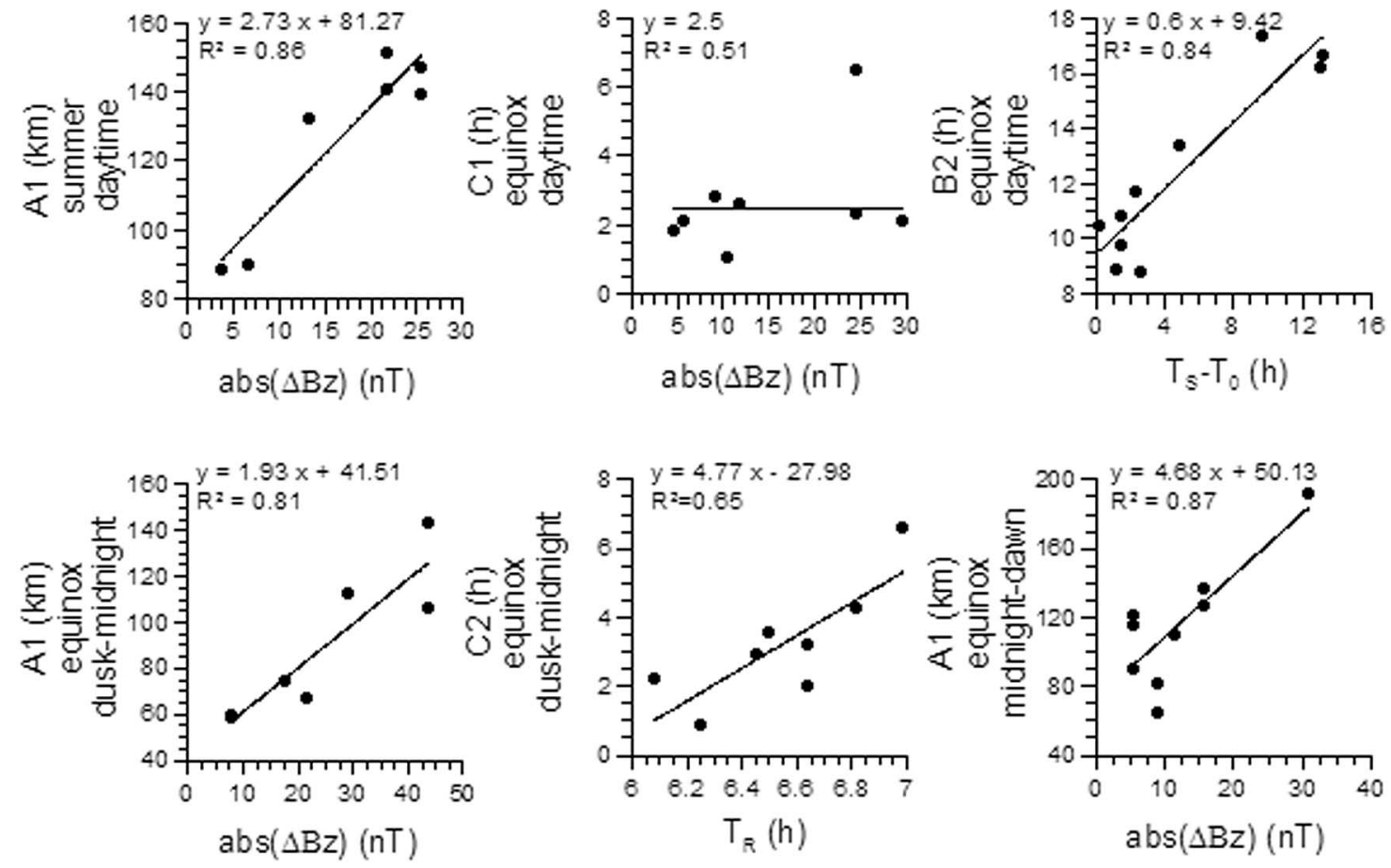

Figure 7. Scatterplots of some of the Ai, Bi and Ci coefficients of the Gaussian function that define the model in relation to the local time, season and interplanetary magnetic field. Solid lines depict the best linear fits of each data pair series, whose equations and coefficients of determination are indicated. $\Delta \mathrm{Bz}$ means the rate of change of the $\mathrm{Bz}$ component of the IMF in $\mathrm{nT}$ as defined into the main text. $\mathrm{T}_{0}$ is the reference time, $T_{R}$ and $T_{S}$ are the sunrise and sunset times respectively in hours.

criterion of Gonzalez and Tsurutani [1987] for predicting intense geomagnetic storms. However, this criterion is useless for real-time applications $-\mathrm{Bz}$ should have values less that $-10 \mathrm{nT}$ lasting for $3 \mathrm{~h}$ or $2.5 \mathrm{~h}$ for solar minimum [Zhang et al., 2006]. The STIM model forecasts ionospheric electron density disturbances in response to IMF conditions in near real time [Tsagouri and Belehaki, 2008; Tsagouri et al., 2009] and it uses the total IMF magnitude (IMF B), its rate of change and the IMF Bz orientation as precursors of the storm effects on the ionospheric peak density. Saiz et al. [2008] have shown that variations of $\mathrm{Bz}$ over a threshold for a certain time interval successfully warns of large Dst hourly variations and that it is possible to alert intense geomagnetic storms only with $\mathrm{Bz}$. We have evaluated if the triggering time criteria used in the STIM model may serve as precursor for the peak height disturbances but the reaction time of $\Delta \mathrm{hmF} 2$ does not fit any clear systematic pattern in relation to the STIM criteria. We have evaluated also different thresholds for variations of $\mathrm{Bz}$ for certain time windows and for the southern orientation of $\mathrm{Bz}$ as potential precursors of $\Delta \mathrm{hmF} 2$ obtaining good results and no false alarms. We have empirically found that a change larger than $20 \mathrm{nT}$ in the $\mathrm{Bz}$ component of the IMF within a time window of $3 \mathrm{~h}$ and a drop of $\mathrm{Bz}$ to $-10 \mathrm{nT}$ successfully alerts the pulse-like in the $\Delta \mathrm{hmF} 2$. Note that the moment when $\mathrm{Bz}$ drops to $-10 \mathrm{nT}$ $(\mathrm{Bz} \leq-10 \mathrm{nT})$ is the so-called as reference time in Section $3.1, \mathrm{~T}_{0}$. Thus we assume that it is necessary to accomplish with the above criteria to predict the pulse-like of $\Delta \mathrm{hmF} 2$; otherwise no $\Delta \mathrm{hmF} 2$ pulse will occur.
[19] We have found different patterns of time-development of $\Delta \mathrm{hmF} 2$ depending on the local time of the ionospheric station at the reference time and on the season (Figure 6); i.e., a sole distinct pulse is observed for those events recorded at the midnight-dawn sector whereas two pulses are observed otherwise. Once we have fixed an alert criterion to predict the pulse-like of $\Delta \mathrm{hmF} 2$, we have evaluated different analytical functions to simulate this two-pulse like behavior and concluded that time dependent Gaussian functions provide the best fits to behavior of $\Delta \mathrm{hmF} 2$. Polynomial and cosine functions have been evaluated also and they provided worse results compared to the Gaussian functions. Thus, we have modeled the $\Delta \mathrm{hmF} 2$ disturbance through two Gaussian functions (equation (1)):

$$
\Delta h m F 2(t)=A_{1} \cdot e^{-\left(t-B_{1}\right)^{2} / C_{1}^{2}}+A_{2} \cdot e^{-\left(t-B_{2}\right)^{2} / C_{2}^{2}}
$$

where $A_{i}, B_{i}$ and $C_{i}$ are the heights, the center and the widths of the Gaussian bells. Qualitatively, the coefficients A represent the strength of the height disturbances, coefficients B relate to the time delay from the baseline to the maxima of the disturbances and the coefficients $\mathrm{C}$ are a measure of the duration of the disturbance.

[20] Prölss [1993] and Deminova et al. [1998] have deduced previously that $\Delta \mathrm{hmF} 2$ disturbances can be simulated using functions whose morphology depends on the energy injection at high latitudes. Moreover, an accurate modeling must consider the main driving mechanisms which relates to the 
Table 2. Coefficients of the Gaussian Functions in Relation to the Local Time and Season ${ }^{\mathrm{a}}$

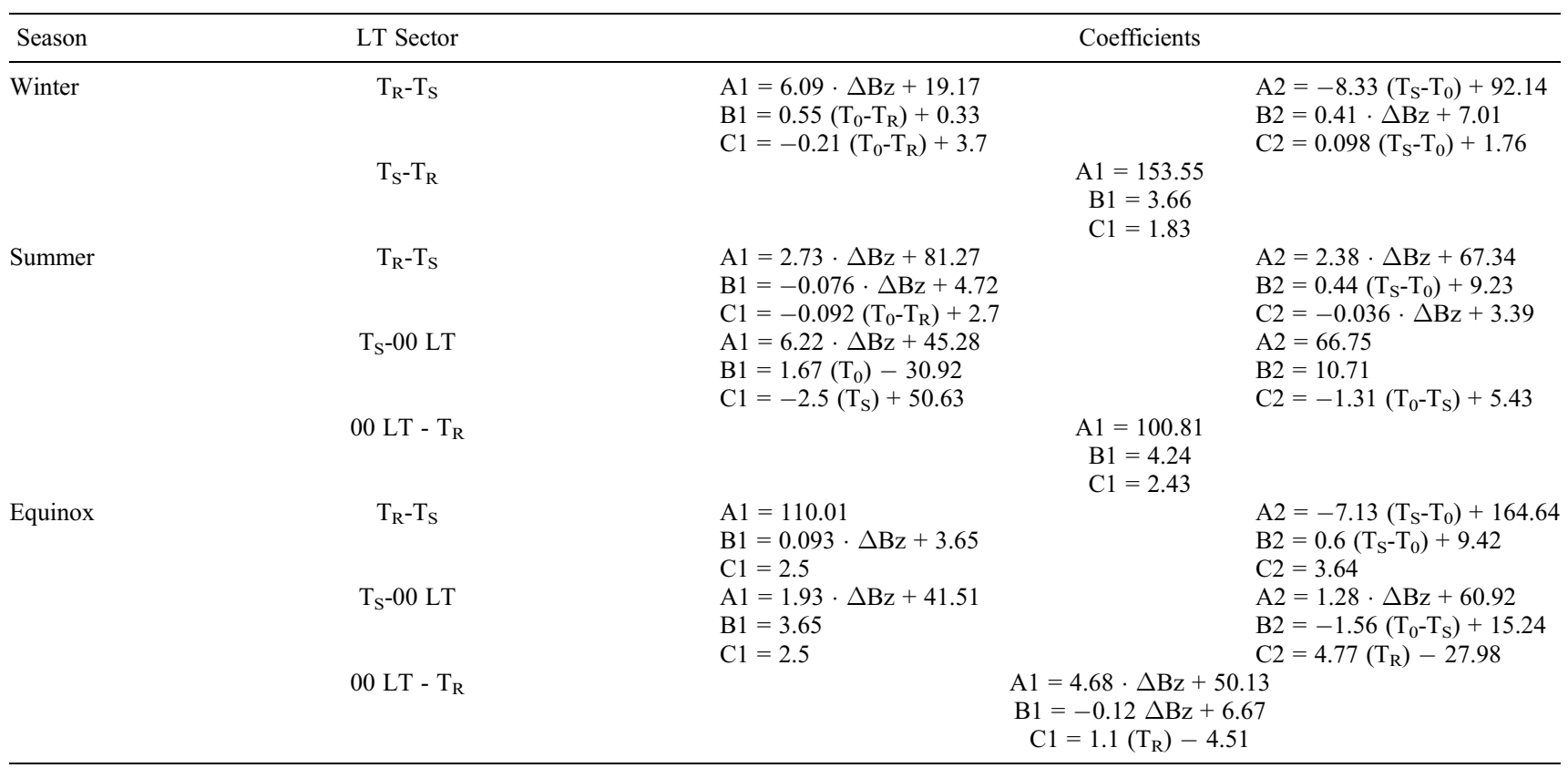

${ }^{\mathrm{a}} \Delta \mathrm{Bz}$ is the absolute value of the rate of change of the $\mathrm{Bz}$ component of the IMF in $\mathrm{nT}$ as defined into the main text. $\mathrm{T}_{0}$ means the so-called "reference" time, $T_{R}$ and $T_{S}$ mean the sunrise and sunset times respectively in hours. $A_{i}$ coefficients are expressed in $k m$ and $B_{i}$ and $C_{i}$ are expressed in hours.

disturbed thermospheric neutral winds and depends on the local time and season [e.g., Fuller-Rowell et al., 1994; Fedrizzi et al., 2008].

[21] Thus, we have fitted the 45 samples of hmF2 disturbances to Gaussian functions which have furnished 45 pairs of coefficients $A_{i}, B_{i}$ and $C_{i}$ (equation (1)). We have investigated the potential dependence of these coefficients with the local time, season and strength of the storm. The 45 sets of coefficients were grouped into different seasons (Winter from December 21 to March 20, Summer from June 21 to September 20, and Equinox from March 21 to June 20 plus from September 21 to December 20) and into different local time sectors (Daytime, Dusk-Midnight and MidnightDown) according to the distinct time-development observed for the pulse-like $\Delta \mathrm{hmF} 2$ (Figure 6). Aiming to obtain a potential relationship of these coefficients with the energy input at high latitudes (strength of the storm), several indices and magnitudes have been checked (i.e., solar wind, IMF and geomagnetic activity data). As pointed out earlier, our experimental results are consistent with the storm scenario described by Prölss [1993] in which the main driving mechanism for the pulse-like $\Delta \mathrm{hmF} 2$ relates to the disturbed thermospheric neutral winds as consequence of the energy deposition at high latitudes. Many studies have used the AE index as a proxy of the energy input at high latitudes during a geomagnetic storm [e.g., Prölss, 1993; Deminova et al., 1998; Prölss and Očko, 2000]. However, the auroral electrojet tends to move to lower latitudes than usual during intense geomagnetic storms and the AE index may be not accurate enough [e.g., Meng, 1984; Khorosheva, 1986; Wang et al., 2008]. The latter fact and that AE is useless for forecasting purposes convinced us to disregard bounding our model to the AE index. It is well known that energy transfer from solar wind to magnetosphere occur by the arrival of a southern IMF via reconnection and large-scale convection and because of fluctuations in the Bz. Kamide [2001] proposes that quasi-steady component of the $\mathrm{Bz}$ is important in enhancing the ring current during geomagnetic storms, while changes, or fluctuations, in $\mathrm{Bz}$ are responsible for initiating substorms. Saiz et al. [2008] have shown that fluctuation in $\mathrm{Bz}$ seems to relate with large Dst variations in the main phase of intense geomagnetic storms. We have observed that those storms with slow varying main phase do not produce significant disturbances at hmF2 (Section 2). This probably indicates the absence of significant changes in $\mathrm{Bz}$ (in agreement with the results of Saiz et al. [2008]) and consequently the absence of substorm activity (in agreement with the results of Kamide [2001]). According to these thoughts, we may speculate that the energy input at high latitude is not enough to launch TADs and generate the pulselike $\Delta \mathrm{hmF} 2$. Thus, we evaluated the potential relationship of the Gaussian coefficients with the rate of change of $\mathrm{Bz}$ and with the local time and seasons.

[22] We have empirically found that the rate of change of the $\mathrm{Bz}$ is the proxy that better relates with the strength, delay and duration of the pulse-like $\Delta \mathrm{hmF} 2$ which are represented by the coefficients $A_{i}, B_{i}$ and $C_{i}$ respectively (equation (1)). In particular, the absolute value of the rate of change of $\mathrm{Bz}$ for the one hour interval preceding the reference time $\mathrm{T}_{0}$ (i.e., $\mid \Delta$ $\left.\mathrm{Bz}|=| \mathrm{Bz}\left(\mathrm{T}_{0}\right)-\mathrm{Bz}\left(\mathrm{T}_{0-1}\right) \mid\right)$. Moreover, we have also found that the coefficients $A_{i}, B_{i}$ and $C_{i}$ depend on the local time and season as well. Figure 7 depicts the relation of some of the coefficients with $|\Delta \mathrm{Bz}|$ and with the local time for different season and local time sectors. Those coefficients that do not present any linear trend with these parameters have been considered as a constant value equal to their respective averages. Although our findings have been obtained empirically they have physical meaning. As pointed out earlier, the fluctuations in the solar wind electric fields are responsible for initiating magnetospheric substorms [e.g., Kamide, 2001] which play significant role on the hmF2 disturbance and the $\mathrm{Bz}$ component of the IMF is the main contributor to the 

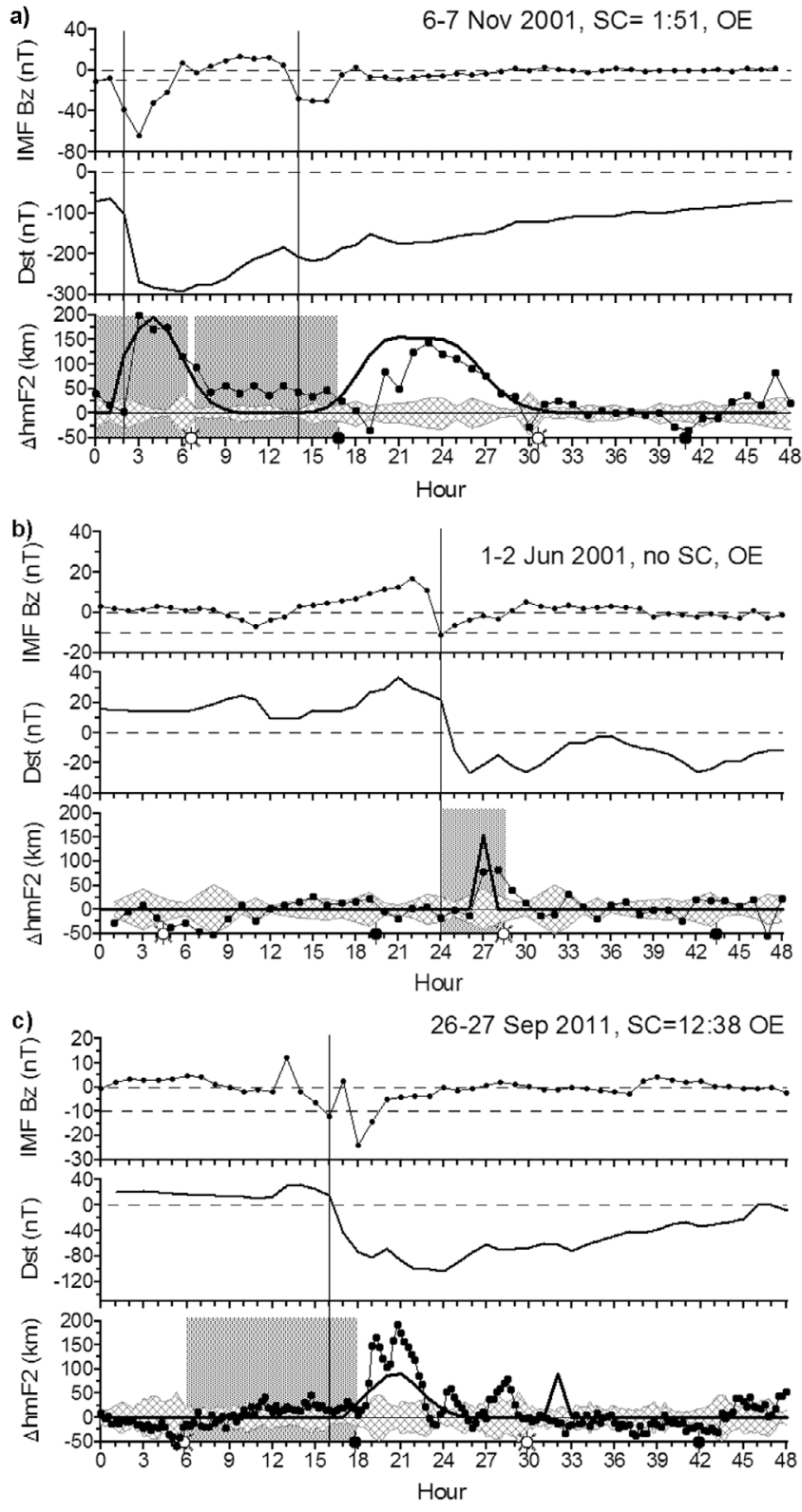

Figure 8. Experimental behavior of $\Delta \mathrm{hmF} 2$ (dotted line) and $\triangle \mathrm{hmF} 2$ model prediction (black line) in comparison with IMF Bz component and Dst index for indicated disturbed time intervals. Shaded areas indicate the local time sector for each case. Vertical black lines indicate the reference time. Error bars correspond to the range of expected variation for a quiet day. White and black suns correspond to sunrise and sunset at ground level respectively. (a) An example of two successive events that occur closely in time; first one of Type A and second one of Type C events. (b) An example of an event that was not used to construct the model ( $\mathrm{Bz} \leq-10 \mathrm{nT}$ for only one hour) but IMF Bz accomplish the conditions to trigger the model. It corresponds to an event of Type A. (c) An example of an event that corresponds to a set of time interval different from that used to construct the model. It corresponds to an event of Type C. effective solar wind-magnetosphere coupling [e.g., Gonzalez and Tsurutani, 1987]. Moreover, the main driving mechanisms for $\Delta \mathrm{hmF} 2$ which relates to the disturbed thermospheric neutral winds depends on the local time and season [e.g., Fuller-Rowell et al., 1994; Fedrizzi et al., 2008]. Table 2 shows the coefficients defining our model for $\Delta \mathrm{hmF} 2$. The few number of samples recorded during winter compared to the other seasons makes not possible getting a more detailed pattern than two LT sectors.

[23] In summary our model for $\Delta \mathrm{hmF} 2$ works as follows. First, the model evaluates the conditions of $\mathrm{Bz}$ to alert if the pulse-like in the $\Delta \mathrm{hmF} 2$ can occur (a change larger than $20 \mathrm{nT}$ in the $\mathrm{Bz}$ within a time window of $3 \mathrm{~h}$ and a drop of $\mathrm{Bz}$ to $-10 \mathrm{nT}$ ). If the above criteria are not fulfilled, the model gets no alarm and it outputs zero values of $\Delta \mathrm{hmF} 2$. If the above criteria are accomplished the model gives a positive alarm and it predicts the pulse-like in the $\Delta \mathrm{hmF} 2$ according to the analytical function described in equation (1) with the coefficients listed in the Table 2. Once the model gives a positive alarm, it cannot provide a successive alarm until the first pulse-like of $\Delta \mathrm{hmF} 2$ had ended. This "standby" time is related with coefficients $C_{1}$ and $B_{1}$. The latter is a compromise to prevent the model reacting for a two-step type storms [Kamide et al., 1998] but to record two consecutive storms closely in time.

\section{Modeling Results}

[24] The above analysis has determined the characteristic behavior of the pulse-like $\Delta \mathrm{hmF} 2$ during intense geomagnetic storms and obtained an analytical model that successfully simulates and predicts the pulse-like $\Delta \mathrm{hmF} 2$ according to interplanetary magnetic field conditions in near real time.

[25] The model provides no false alarms using the criteria to alert the model but it reduces the number of detected events. According to this, the model alerts 38 times for the time interval from 1995 to 2007 (i.e., it detects 38 geomagnetically disturbed periods in which the ionosphere should raise). However, only 28 of these intervals have contemporary interplanetary magnetic field and ionospheric data available. In addition, either of the ionospheric stations, EA or OE, report data gaps in some of the above intervals resulting 35 samples that record pulse-like $\Delta \mathrm{hmF} 2$ (12 at EA and 23 at $\mathrm{OE}$ ). As a result, the model successfully predicts 30 of the 35 samples of pulse-like $\Delta \mathrm{hmF} 2$. Thus, the near real time prediction model has a $86 \%$ of success in the event detection. Figure 8 depicts some examples of the model performance for particular events which are observed for different seasons and local time sectors. Figure 8a shows an example for two successive events that had occurred closely in time; the first one of Type A and the second one of Type C events (Section 3.3). Figure 8b shows an example for an event that was not into the statistics, although it occurred for the time interval 1995-2007, because $\mathrm{Bz} \leq-10 \mathrm{nT}$ lasted for one hour only. However, Bz accomplish the criteria to positively alarm the model and it fits to an event of Type A. Finally, Figure 8c shows an example for an event that has occurred recently and outside the time interval of the statistics, corresponding to an event of Type C.

[26] We have computed the Root Mean Square Error (RMSE) between the predicted $\Delta \mathrm{hmF} 2$ and the experimental data to assess the goodness of the real-time prediction model. 


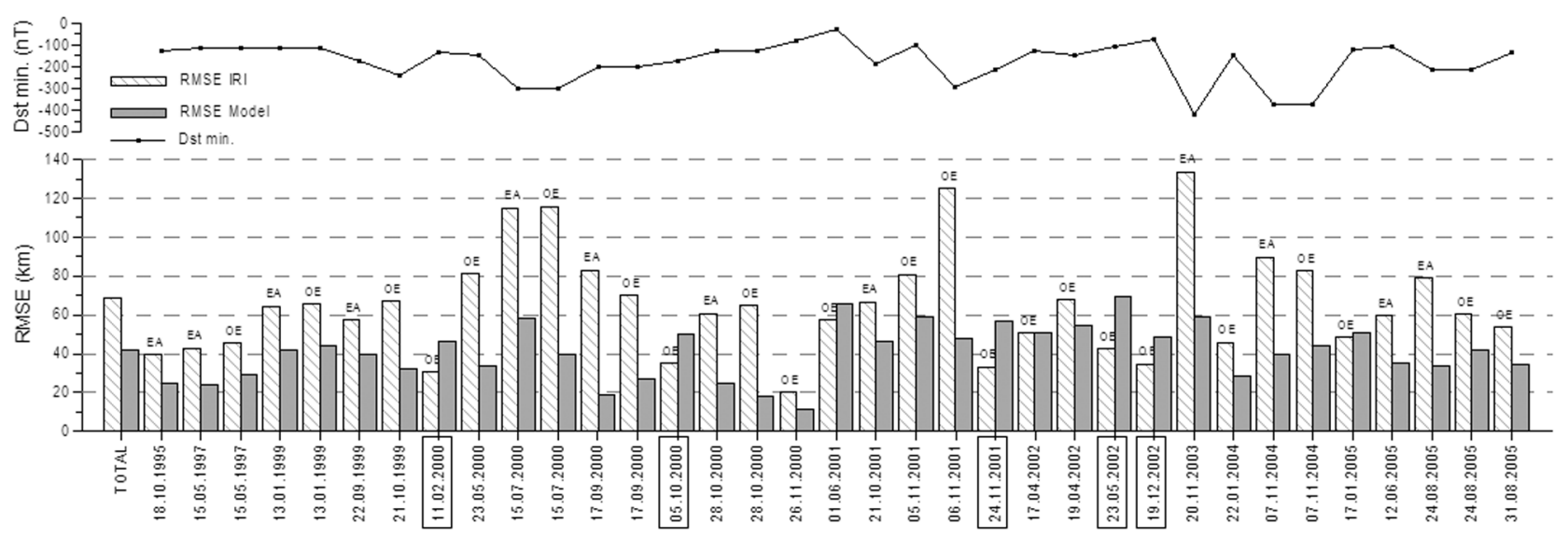

Figure 9. Comparison of the RMSE provided by IRI predictions (light gray) with the RMSE provided by the real-time disturbance model (dark gray). OE corresponds to the events observed at the "Observatorio del Ebro" and EA to those observed at "El Arenosillo." Black boxes indicate those cases in which the model prediction fails. The minimum Dst is depicted in the upper part of the panel showing the storm intensity.

The RMSE was calculated for a time interval of $24 \mathrm{~h}$ elapsed from the reference time:

$$
R M S E=\sqrt{\frac{\sum\left[f\left(x_{i}\right)-y_{i}\right]^{2}}{n}}
$$

where $\mathrm{n}$ is the total number of data, $\mathrm{f}\left(\mathrm{x}_{\mathrm{i}}\right)$ is the function value, and $y_{i}$ is the corresponding experimental value. The RMSE of the real-time prediction model have been compared with the RMSE provided by the STORM correction model of the IRI [Araujo-Pradere et al., 2002; Araujo-Pradere and FullerRowell, 2002]. Figure 9 depicts the above results for all the samples detected by the model. Note that the RMSE provided by the real-time $\Delta \mathrm{hmF} 2$ model is lower than $40 \mathrm{~km}$ for most of the samples. This value is equivalent to the value of $2 \sigma$, where $\sigma$ is the standard deviation of the quiet days in relation to the average reference quiet day. Therefore, the application of real-time empirical model for predicting $\Delta \mathrm{hmF} 2$ gives satisfactory results.

\section{Summary and Concluding Remarks}

[27] Little number of investigations has been made to date to develop a hmF2 disturbance model caused by the geomagnetic storms or to validate the storms effects on the hmF2 [e.g., Deminova et al., 1998; Fedrizzi et al., 2008]. The shortage on such hmF2 disturbance modeling is mostly due to the scarcity of true height data and/or to an inaccurate formulation of the hmF2 characteristic [e.g., Shimazaki, 1955; Prölss and Očko, 2000]. The large amount of data of good quality recorded at midlatitude stations in Spain make possible obtaining the characteristic behavior of the hmF2 disturbance caused by intense geomagnetic storms in relation to the local-time, season and conditions of the IMF. The good correlation between the pulse-like $\Delta \mathrm{hmF} 2$ and the proxies of the energy input at auroral latitudes jointly with the delayed response of the ionosphere respect to the disturbance of the IMF support the storm scenario proposed by Prölss [e.g., Prölss, 1993; Fuller-Rowell et al., 1994]: the TADs of auroral origin and changes in the thermospheric wind are the main physical mechanisms driving equatorward-directed and vertical winds which in turn move the plasma along the magnetic field lines and raise the ionospheric peak height.

[28] The systematic pulse-like shape of the $\Delta \mathrm{hmF} 2$ caused by the geomagnetic storms has been related to the local time, season and conditions of the interplanetary magnetic field. This resulted in a real-time forecasting tool which models the $\Delta \mathrm{hmF} 2$ by analytical time-dependent functions (equation (1)) whose coefficients depend on the configuration of the IMF, the local time and season (Table 2).

[29] The obtained empirical model predicts the pulse-like $\Delta \mathrm{hmF} 2$ with an average RMSE comparable to 2 times the values of the standard deviation of the quiet days in relation to the average reference quiet day and without false alarms. This empirical model can be used as a prediction tool for real-time Space Weather applications due to the current availability of satellite records of IMF in near real time. To best of our knowledge, this fact would place this model as unique in its category. It should be noticed that the current model pretends modeling and predicting the $\Delta \mathrm{hmF} 2$ during intense geomagnetic storm. However, it is known that current IRI model works reasonably well predicting hmF2 under quiet conditions for midlatitudes [e.g., Magdaleno et al., 2011] and it fits reasonably well to our experimental reference days (Figure 1). Adding the results of our $\Delta \mathrm{hmF} 2$ to the quiet time prediction of the IRI one would obtain a real-time tool for predicting $\mathrm{hmF} 2$ under both, quiet and disturbed conditions. The latter is out of the scope of the current investigation and might be evaluated in future studies.

[30] Although this analysis has been carried out with ionospheric data gathered in the Iberian Peninsula, the behavior of the pulse-like $\Delta \mathrm{hmF} 2$ during geomagnetic storms has been found to be equivalent to other midlatitude stations [e.g., Paznukhov et al., 2009]. We have evaluated how behaves the $\Delta \mathrm{hmF} 2$ model at other latitudes and longitudes of Europe for several geomagnetic storm events. We have analyzed the pulse-like $\Delta \mathrm{hmF} 2$ observed from the ionospheric stations at Chilton $\left(51.5^{\circ} \mathrm{N}, 359.4^{\circ} \mathrm{E}\right)$, Pruhonice $\left(50.5^{\circ} \mathrm{N}, 14.6^{\circ} \mathrm{E}\right)$, San Vito $\left(40.6^{\circ} \mathrm{N}, 17.8^{\circ} \mathrm{E}\right)$ and Athens $\left(38.0^{\circ} \mathrm{N}, 23.5^{\circ} \mathrm{E}\right)$ for the storms occurred on 20-21/11/2003, 22-23/01/2004, 07-08/11/ 2004 and 24-25/08/2005. The results indicate that the model fits the pulse-like $\Delta \mathrm{hmF} 2$ for whichever of the above 


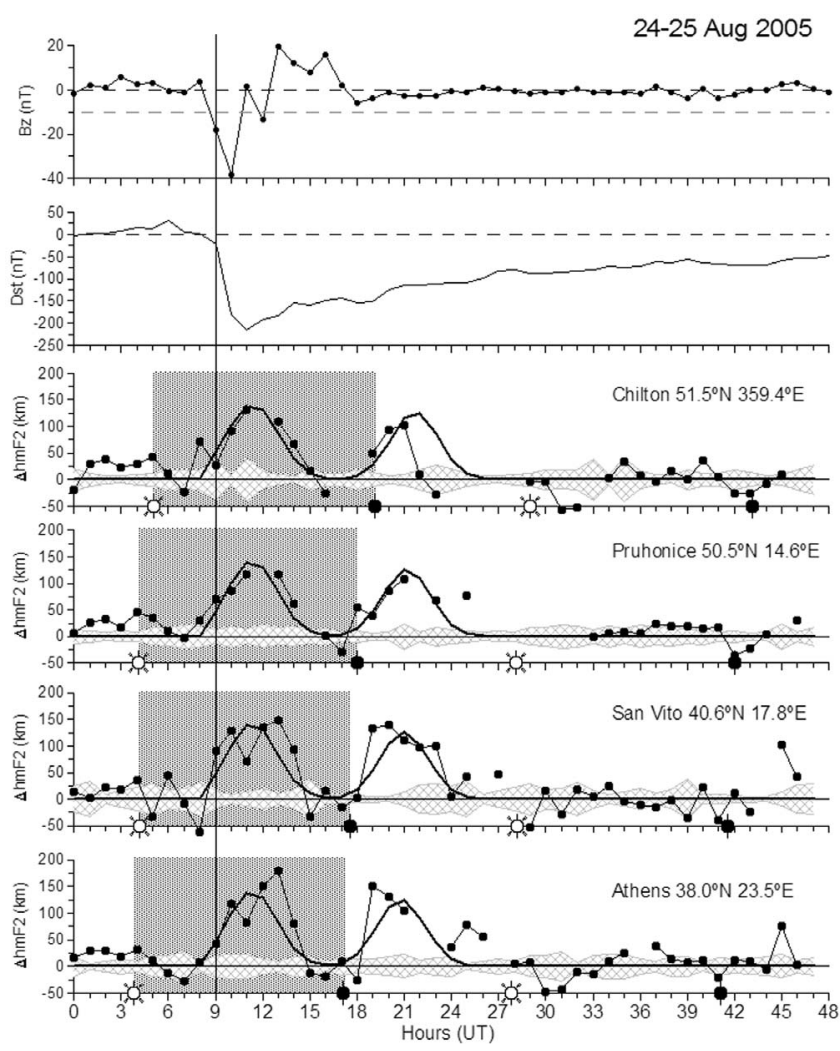

Figure 10. Experimental behavior of $\Delta \mathrm{hmF} 2$ (dotted line) and $\triangle \mathrm{hmF} 2$ model prediction (black line) in comparison with IMF Bz component and Dst index for 24-25 August 2005 disturbed period at different European locations. Shaded areas indicate the local time sector for each case. Vertical black lines indicate the reference time. Error bars correspond to the range of expected variation for a quiet day. White and black suns correspond to sunrise and sunset at ground level respectively.

ionospheric stations and storm events but exhibits slight shortcomings for the stations located at higher latitudes (Figure 10). Thus, this empirical model can be extended to a wider latitude range. However, further analyses of good quality of $\mathrm{hmF} 2$ data, provided by either ionosondes or satellite, are needed to assess the latitude range of validity of the currently presented modeling approach.

[31] Another improvement of the model can result with the analysis of higher sampling data for both ionospheric and IMF magnitudes which are of 1-h sampling in the present investigation. The later would be possible with the advent new data and with the available data of recent times.

[32] Acknowledgments. This research has been partly supported by Spanish projects 2009SGR507 and CTM2010-21312-C03-01. The authors thank the ACE MAG and SWEPAM instrument teams and the ACE Science Center for providing the ACE data, the NASA/ Goddard Space Flight Center Space Physics Data Facility OMNIWeb Plus data and service team form preparing good quality ACE data, the U.S. Department of Commerce, NOAA, Space Weather Prediction Center the Space for preparing near real time ACE solar wind data and the Kyoto WDC for providing geomagnetic activity indices. The authors want to acknowledge the useful comments of the referees that improve the quality of this manuscript.
[33] Robert Lysak thanks Elena Saiz and another reviewer for their assistance in evaluating this paper.

\section{References}

Araujo-Pradere, E. A., and T. J. Fuller-Rowell (2002), STORM: An empirical storm-time ionospheric correction model, 2, Validation, Radio Sci., 37(5), 1071, doi:10.1029/2002RS002620.

Araujo-Pradere, E. A., T. J. Fuller-Rowell, and M. V. Codrescu (2002), STORM: An empirical storm-time ionospheric correction model: 1. Model description, Radio Sci., 37(5), 1070, doi:10.1029/2001RS002467. Araujo-Pradere, E. A. T. J. Fuller-Rowell, and D. Bilitza (2004), Time Empirical Ionospheric Correction Model (STORM) response in IRI2000 and challenges for empirical modeling in the future, Radio Sci., 39, RS1S24, doi:10.1029/2002RS002805.

Balan, N., K. Shiokawa, Y. Otsuka, T. Kikuchi, D. Vijaya Lekshmi, S. Kawamura, M. Yamamoto, and G. J. Bailey (2010), A physical mechanism of positive ionospheric storms at low latitudes and midlatitudes, J. Geophys. Res., 115, A02304, doi:10.1029/2009JA014515.

Bilitza, D. (2001), International Reference Ionosphere 2000, Radio Sci., 36(2), 261-275, doi:10.1029/2000RS002432.

Blanc, M., and A. D. Richmond (1980), The ionospheric disturbance dynamo, J. Geophys. Res., 85(A4), 1669-1686, doi:10.1029/JA085iA04p01669.

Buonsanto, M. J. (1999), Ionospheric storms: A review, Space Sci. Rev., 88 , 563-601, doi:10.1023/A:1005107532631.

Deminova, G. F., V. M. Shashunkina, and E. E. Goncharova (1998), A global empirical model of effects of large-scale internal gravity waves in the night-time ionosphere, J. Atmos. Sol. Terr. Phys., 60, 227-245, doi:10.1016/S1364-6826(97)00050-3.

Denton, M. H., T. Ulich, and E. Turunen (2009), Modification of midlatitude ionospheric parameters in the F2 layer by persistent high-speed solar wind streams, Space Weather, 7, S04006, doi:10.1029/2008SW000443.

Fedrizzi, M., T. J. Fuller-Rowell, N. Maruyama, M. Codrescu, and H. Khalsa (2008), Sources of $F$-region height changes during geomagnetic storms at mid latitudes, in Midlatitude Ionospheric Dynamics and Disturbances, Geophys. Monogr. Ser, vol. 181, edited by P. M. Kintner, Jr. et al., pp. 247-258, AGU, Washington, D. C.

Fuller-Rowell, T. J., M. V. Codrescu, R. J. Moffett, and S. Quegan (1994), Response of the thermosphere and ionosphere to geomagnetic storms, J. Geophys. Res., 99(A3), 3893-3914, doi:10.1029/93JA02015.

Fuller-Rowell, T. J., M. V. Codrescu, H. Rishbeth, R. J. Moffett, and S. Quegan (1996), On the seasonal response of the thermosphere and ionosphere to geomagnetic storms, J. Geophys. Res., 101(A2), 2343-2353, doi:10.1029/95JA01614.

Fuller-Rowell, T. J., M. Codrescu, M. Maruyama, M. Fedrizzi, E. AraujoPradere, S. Sazykin, and G. Bust (2007), Observed and modeled thermosphere and ionosphere response to superstorms, Radio Sci., 42, RS4S90, doi:10.1029/2005RS003392.

Gonzalez, W. D., and B. T. Tsurutani (1987), Criteria of interplanetary parameters causing intense magnetic storms (Dst $<-100 \mathrm{nT}$ ), Planet. Space Sci., 35, 1101-1109, doi:10.1016/0032-0633(87)90015-8.

Gonzalez, W. D., J. A. Joselyn, Y. Kamide, H. W. Kroehl, G. Rostoker, B. T. Tsurutani, and V. M. Vasyliunas (1994), What is a geomagnetic storm?, J. Geophys. Res., 99(A4), 5771-5792, doi:10.1029/93JA02867.

Heelis, R. A. (2004), Electrodynamics in the low and middle latitude ionosphere: A tutorial, J. Atmos. Sol. Terr. Phys., 66, 825-838, doi:10.1016/ j.jastp.2004.01.034

Huang, C.-S., J. C. Foster, and M. C. Kelley (2005), Long-duration penetration of the interplanetary electric field to the low-latitude ionosphere during the main phase of magnetic storms, J. Geophys. Res., 110, A11309, doi:10.1029/2005JA011202.

Huang, X., and B. W. Reinisch (1996a), Vertical electron density profiles from the Digisonde network, Adv. Space Res., 18, 121-129, doi:10.1016/02731177(95)00912-4.

Huang, X., and B. W. Reinisch (1996b), Vertical electron density profiles from Digisonde ionograms: The average representative profile, Ann. Geofis., 39(4), 751-756.

Kamide, Y. (2001), Interplanetary and magnetospheric electric fields during geomagnetic storms: What is more important, steady-state fields or fluctuating fields?, J. Atmos. Sol. Terr. Phys., 63, 413-420, doi:10.1016/ S1364-6826(00)00176-0.

Kamide, Y., N. Yokoyama, W. Gonzalez, B. T. Tsurutani, I. A. Daglis, A. Brekke, and S. Masuda (1998), Two-step development of geomagnetic storms, J. Geophys. Res., 103(A4), 6917-6921, doi:10.1029/97JA03337.

Kelley, M. C., M. N. Vlasov, J. C. Foster, and A. J. Coster (2004), A quantitative explanation for the phenomenon known as storm-enhanced density, Geophys. Res. Lett., 31, L19809, doi:10.1029/2004GL020875. 
Khorosheva, O. V. (1986), Relation of the magnetospheric disturbances to the parameters of the interplanetary medium, Geomagn. Aeron., Engl. Transl., 26, 447-453.

Lei, J., W. Wang, A. G. Burns, S. C. Solomon, A. D. Richmond, M. Wiltberger, L. P. Goncharenko, A. Coster, and B. W. Reinisch (2008), Observations and simulations of the ionospheric and thermospheric response to the December 2006 geomagnetic storm: Initial phase, J. Geophys. Res., 113, A01314, doi:10.1029/2007JA012807.

Lu, G., L. P. Goncharenko, A. D. Richmond, R. G. Roble, and N. Aponte (2008), A dayside ionospheric positive storm phase driven by neutral winds, J. Geophys. Res., 113, A08304, doi:10.1029/2007JA012895.

Magdaleno, S., D. Altadill, M. Herraiz, E. Blanch, and B. de la Morena (2011), Ionospheric peak height behavior for low, middle and high latitudes: A potential empirical model for quiet conditions-Comparison with the IRI-2007 model, J. Atmos. Sol. Terr. Phys., 73, 1810-1817, doi:10.1016/j.jastp.2011.04.019.

Mendillo, M. (2006), Storms in the ionosphere: Patterns and processes for total electron content, Rev. Geophys., 44, RG4001, doi:10.1029/ 2005RG000193.

Meng, C. I. (1984), Dynamic variation of the auroral oval during intense magnetic storms, J. Geophys. Res., 89(A1), 227-235, doi:10.1029/ JA089iA01p00227.

Parkinson, W. D. (1983), Introduction to Geomagnetism, Scottish Academic, Edinburgh.

Paznukhov, V. V., D. Altadill, and B. W. Reinisch (2009), Experimental evidence for the role of the neutral wind in the development of ionospheric storms in midlatitudes, J. Geophys. Res., 114, A12319, doi:10.1029/2009JA014479.

Prölss, G. W. (1993), On explaining the local time variation of ionospheric storm effects, Ann. Geophys., 11, 1-9.

Prölss, G. W. (1995), Ionospheric F region storms, in Handbook of Atmospheric Electrodynamics, edited by H. Volland, pp. 195-248, CRC Press, Boca Raton, Fla.

Prölss, G. W., and M. Očko (2000), Propagation of upper atmospheric storm effects towards lower latitudes, Adv. Space Res., 26, 131-135, doi:10.1016/S0273-1177(99)01039-X.
Rishbeth, H. (1991), F-region storms and thermospheric dynamics, J. Geomagn. Geoelectr., 43, 513-524, doi:10.5636/jgg.43.Supplement1_ 513.

Rostoker, G., S.-I. Akasofu, J. Foster, R. A. Greenwald, Y. Kamide, K. Kawasaki, A. T. Y. Lui, R. L. McPherron, and C. T. Russell (1980), Magnetospheric substorms: Definition and signatures, J. Geophys. Res., 85(A4), 1663-1668, doi:10.1029/JA085iA04p01663.

Saiz, E., C. Cid, and Y. Cerrato (2008), Forecasting intense geomagnetic activity using interplanetary magnetic field data, Ann. Geophys., 26 , 3989-3998, doi:10.5194/angeo-26-3989-2008.

Shimazaki, T. (1955), Worldwide daily variations in the height of the maximum electron density in the ionospheric F2 layer, J. Radio Res. Lab. Jpn., 2(7), 85-97.

Spiro, R. W., R. A. Wolf, and B. G. Fejer (1988), Penetration of high-latitude-electric-field effects to low latitudes during SUNDIAL 1984, Ann. Geophys., 6, 39-49.

Tsagouri, I., and A. Belehaki (2006), A new empirical model of middle latitude ionospheric response for space weather applications, Adv. Space Res., 37(2), 420-425, doi:10.1016/j.asr.2005.07.048.

Tsagouri, I., and A. Belehaki (2008), An upgrade of the solar wind driven empirical model for the middle latitude ionospheric storm time response, J. Atmos. Sol. Terr. Phys., 70, 2061-2076, doi:10.1016/j.jastp.2008.09.010.

Tsagouri, I., K. Koutroumbas, and A. Belehaki (2009), Ionospheric foF2 forecast over Europe based on an autoregressive modeling technique driven by solar wind parameters, Radio Sci., 44, RS0A35, doi:10.1029/ 2008RS004112.

Wang, H., H. Lühr, A. Ridley, P. Ritter, and Y. Yu (2008), Storm time dynamics of auroral electrojets: CHAMP observation and the Space Weather Modeling Framework comparison, Ann. Geophys., 26, 555-570, doi:10.5194/angeo-26-555-2008.

Zhang, J., M. W. Liemohn, J. U. Kozyra, M. F. Thomsen, H. A. Elliott, and J. M. Weygand (2006), A statistical comparison of solar wind sources of moderate and intense geomagnetic storms at solar minimum and maximum, J. Geophys. Res., 111, A01104, doi:10.1029/2005JA011065. 